\title{
Téoros
}

Revue de recherche en tourisme

\section{La croisière océanique à Québec}

\section{Henri A. Jamet}

Volume 12, numéro 1, mars 1993

Québec, capitale et région touristiques

URI : https://id.erudit.org/iderudit/1078198ar

DOI : https://doi.org/10.7202/1078198ar

Aller au sommaire du numéro

\section{Éditeur(s)}

Université du Québec à Montréal

\section{ISSN}

0712-8657 (imprimé)

1923-2705 (numérique)

Découvrir la revue

Citer cet article

Jamet, H. A. (1993). La croisière océanique à Québec. Téoros, 12(1), 24-25.

https://doi.org/10.7202/1078198ar d'utilisation que vous pouvez consulter en ligne.

https://apropos.erudit.org/fr/usagers/politique-dutilisation/ 


\title{
La croisière océanique à Québec
}

\author{
Henri A. Jamet*
}

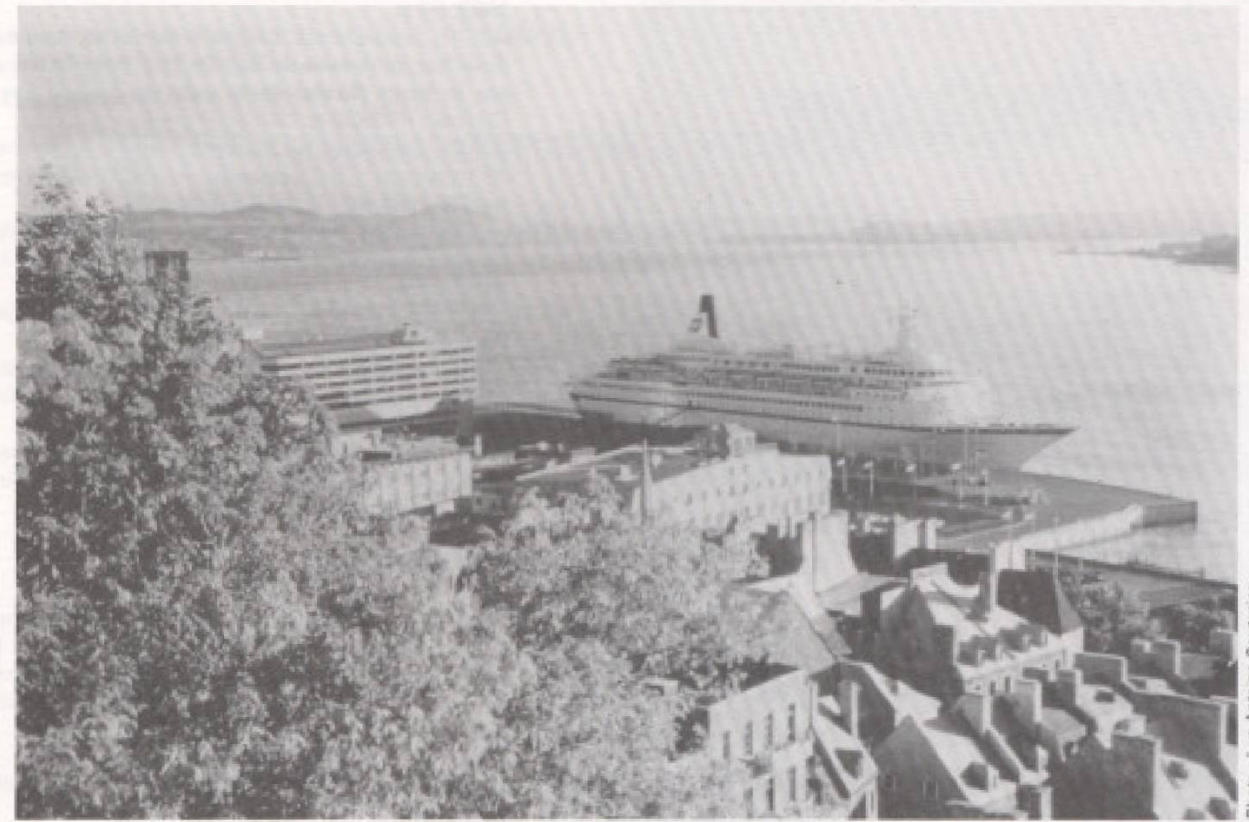

Le port de Quebec ... est le plus attrayant de la cổe Est du Canada pour la croisière océnaique.

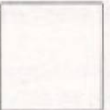

La croisière ockanique est devenue le produit touristique mondial qui a connu le taux de croissance le plus spectaculaire et le plus soutenu de l'industrie touristique, passant de 500000 passagers en 1970 à 4000000 passagers en 1992.

L'augmentation du nombre de passagers a été de $800 \%$ pour cette période. Cela représente une augmentation annuelle moyenne composee de $10 \%$.

L'industrie de la croisière exploite 36 destinations réparties d'après les quatre zones principales où elles ont lieu:

- les croisières en mer chaudes;

- les croisières en mer tempérées;

- les croisières en mer froides;

- les croisières fluviales.

Les 36 destinations sont exploitées ou desservies devrait-on dire par 35 compagnies maritimes membres de la CLIA (Cruises Lines International Association).

Monsieur Henri A. Jamet est délégué régional. pourle Nord-du-QuAbec, duministereduTourisme.

\section{La flotte}

Laflottemondiale des paquebots de croisière (membres de la CLIA) totalisait 161 paquebots en 1992, qui ont une capacité totale de 100000 couchettes.

Les chantiers navals ont été très actifs en 1992 (France, Italie, Finlande principalement). Vingt paquebots ont ainsi été construits et lancés en 1992, pour un coût total de 2 milliards, 951 millions de dollars US.

Le plus cher, le Coste Classica, 50000 tonnes - 1300 passagers, a coûté 325 MS US. Le plus gros, le Majesty of the Seas, 75000 tonnes - 2534 passagers, a coûté $285 \mathrm{M} \$$ US.

\section{Projections de l'industrie}

L'industrie des croisières projette une importante croissance pour la prochaine décennie, soit:

- une clientèle évaluée, selon la CLIA, à 10000000 depassagers pour l'an 2000;

- un marché potentiel de 40000000 de passagers, dont 35000000 seront Américains, suivant les mêmes sources;
- 100 nouveaux paquebots à construire d'ici l'an 2000.

Pour assurer l'atteinte de ces objectifs, l'industrie a dépensé $300 \mathrm{MS}$ US en publicité en 1992, soit 75 \$ par passager. En Amérique du Nord seulement, les forfaits-croisières sont vendus par 22000 grossistes et agents de voyages détaillants.

\section{La part du Saint-Laurent dans la croisière}

Le fleuve Saint-Laurent, avec son golfe, ses affluents, malgré leurs nombreux attraits tels le rocher Percé, l'Ile Bonaventure, la Baiede-Gaspé, l'Ile d'Anticosti, le Saguenay, Québec, les baleines, etc., ont été les grands négligés de la croisière océanique jusqu'en 1980.

En 1992, le fleuve c'est-à-dire les ports de Québec et de Montréal se partageaient $1 \%$ du volume de la croisière oceanique, tandis que les croisières de l'Alaska, avec 250000 passagers, en accaparaient $6 \%$, soit 6 fois plus.

Un autre élément qui renforce ces deux constats pessimistes nous est fourni par une absence surprenante de statistiques sur la croisière occanique sur le Saint-Laurent avant 1984. Ces dernières sont pourtant disponibles de façon exhaustives pour les croisières de l'Alaska depuis 1957 et les croisières de l'Antarctique depuis 1958.

\section{Le port de Québec}

A la position suivante: latitude: $46 \mathrm{eme}$ 49èmedegré Nord; longitude: 71ème-72̀me degré Ouest; Québec est le berceau de la civilisation française en Amérique du Nord. La ville intra-muros a été reconnue comme site du patrimoine mondial par I'UNESCO.

Le port de Québec offre plusieurs quais pour la croisière: le quai 21 mesure 206 mètres de long et on y trouve une profondeur à marée basse de 11,7 mètres. Le quai 22 mesure 325 mètres de long, avec une profondeur à marée basse de 10,7 mètres. 


\section{La croisière océanique au port de Québec}

Mêmesisa part demarchéest faible, Québec n'en présente pas moins déjà une activité de croisière importante (tableau 1).

Le port de Québec, situé stratégiquement entre Montréal et le fjord du Saguenay, est le plus attrayant de la cote Est du Canadla pour la croisière océanique; c'est aussi le plus fréquenté (tableau 2).

\section{Les croisières sur le Saint-Laurent et celles vers l'Alaska}

Les performances de la croisière océanique sur le Saint-Laurent depuis 1985 sont encourageantes; la clientèle des passagers a augmenté de $340 \%$ en 8 saisons. Par contre, elles sont encore modestes en valeur absolue par rapport aux croisières vers l'Alaska qui ont débuté en 1957, bien avant celles du Saint-Laurent (95 000 passagers en 1980 pour l'Alaska en comparaison de 11819 passagers en 1985 pour Québec). Le coquitlam de la Union Steam, lové par le pilote de brousse Charles B. West, transporta 2500 passagers en 1957 en Alaska à partir de Vancouver. Trente-quatre ans plus tard (1991), la flotte de l'Alaska composée de 24 paquebots en transportait 245000 ; le quart de million était dépassé légèrementen 1992. Le demi-million est prévu pour l'an 2000.

Sur le Saint-Laurent, les mêmes prévisions pour le port de Québec annoncent un volume de 100000 passagers; le déficit du SaintLaurent va donc s'accentuer d'année en année par rapport aux croisières vers l'Alaska.

\section{Les facteurs du choix d'une escale}

Selon les propos du président de l"Association de lacroisièreFloride-Caraibes (FCCA), quatre facteurs entrent en ligne de compte dans le choix d'une destination-croisièrepour un armateur:

- les qualités des infrastructures portuaires:

- les attraits du lieu d'escale et des services touristiques fournis;

- la localisation du port;

- la renommée de la destination.

Le port de Québec répond plutôt bien à ces exigences. Cependant, il y a encore des progrè̀s à réaliser au niveau de:

\section{TABLEAU 1}

Nombre de passagers en croisière océanique

\begin{tabular}{lcc}
\hline Année & Passagers & Passagers \\
\hline 1984 & 11819 & 51 \\
1985 & 14430 & 47 \\
1986 & 31552 & 67 \\
1987 & 26012 & 100 \\
1988 & 20295 & 79 \\
1989 & 32174 & 28 \\
1990 & 48083 & 28 \\
1991 & 38241 & 50 \\
1992 & 2207 & 67 \\
\hline
\end{tabular}

222606
- l'accueil aux passagers (animation sur les quais);

- l'amélioration de l'infrastructure portuaire;

- l'embellissement physique du port;

- l'information touristique a bord des navires.

\section{Perspectives de développement} pour Québec et le Saint-Laurent

Leretard accumulé par rapport aux croisières vers l'Alaska, qui peuvent servir de modèle de développement, est devenu presque insurmontable; d'où l'intérêt de savoir partir à temps pour développer un nouveau produit touristique.

Cependant, il y a des éléments positifs qui pourraient contribuer à accélérer le rythme de la croissance des croisières sur le SaintLaurent et à Québec:

- les armateurs recherchent de nouvelles destinations peu encombrées;

- lenombre de passagers participantà des croisières océaniques augmente en moyenne de $10 \%$ par année;

- les croisières fluviales sont de plus en plus recherchées par les passagers et les armateurs (13 armateurs exploitent ces destinations);

- la législation du jeu dans la province de Québec, à partir de 1993, permettra d'attirer les armateurs qui fuyaient nos eaux; en effet, jusqu'en 1992, les jeux d'argent étaient une activité illégale au Canada et les casinos, à bord des bateaux, étaient fermés en entrant dans les eaux canadiennes;

- les autorités portuaires de Québec, Montréal, Trois-Rivières, Sept-Iles, Gaspé, Chandler, Percé s'intéressent
TABLEAU 2 : Fréquentation des ports de la côte Est du Canada

Port:

Québec, P.Q. Nombre de paquebots

Montréal, P.Q.
Halifax, N.E.

Sydney, N.E.

Charlottetown, I.P.E.

St John, T.N.

St Anthony, T.N

Corner Brook, T.N.

St John's, N.B.

Gaspé, P.Q.
450

253

231

183

76

16

27

23 depuis 1986 au développement de la croisière océanique;

- les ports de Québec et de Montréal ont subi des restaurations importantes qui les rendent plus attrayants.

Toutefois, parmi les facteurs qui handicapent encore le développement de la croisière, il y a deux éléments importants à retenir:

- les droits portuaires de Québec sont parmi les plus élevés en Amérique du Nord, auxquels il faut rajouter les frais de pilotage sur le Saint-Laurent:

- il y a un ensemble de lois et de règlements qui contribuenta la non-viabilité de la croisière sous pavillon canadien et qui tiennentéloignés certains armateurs êtrangers, mềme sices règlements visent avant tout la sécurité des bateaux

\section{RÉFEERENCES}

JAMET, Henri A, Les croisières polaires - Antarctique, Aretique, Alaska, ministère du Tourisme, avvi 1992.

THE ECONOMIC PLANNING GROUP OF CANADA, Analyse de l'état de l'industrie des croisietres et des excursions sur les Grands Lacs, le flewve Saint-Laurent et leurs voies navigables de jonction. Rapport princpal. Tome I, Los croisidres, mars 1991. 